\title{
Borderline Personality Features in Students: the Predicting Role of Schema, Emotion Regulation, Dissociative Experience and Suicidal Ideation
}

\author{
Seyede Fateme Sajadi ${ }^{1,2,}$; Nasrin Arshadi ${ }^{1}$; Yadolla Zargar ${ }^{1}$; Mahnaz Mehrabizade Honarmand ${ }^{1}$; \\ Zahra Hajjari $^{3}$ \\ ${ }^{1}$ Department of Psychology, Shahid Chamran University of Ahvaz, Ahvaz, IR Iran \\ ${ }^{2}$ Young Researchers and Elite Club, Shiraz, IR Iran \\ ${ }^{3}$ Department of Preventive Medicine, Faculty of Medicine, University of Malaya, Kuala Lumpur, Malaysia \\ *Corresponding author: Seyede Fateme Sajadi, Department of Psychology, Shahid Chamran University of Ahvaz, Ahvaz, IR Iran. Tel: +98-7132306089, E-mail: f-sajadi@mscstu.scu.ac.ir
}

Received: May 5, 2014; Revised: August 6, 2014; Accepted: August 17, 2014

\begin{abstract}
Background: Numerous studies have demonstrated that early maladaptive schemas, emotional dysregulation are supposed to be the defining core of borderline personality disorder. Many studies have also found a strong association between the diagnosis of borderline personality and the occurrence of suicide ideation and dissociative symptoms.

Objectives: The present study was designed to investigate the relationship between borderline personality features and schema, emotion regulation, dissociative experiences and suicidal ideation among high school students in Shiraz City, Iran.

Patients and Methods: In this descriptive correlational study, 300 students (150 boys and 150 girls) were selected from the high schools in Shiraz, Iran, using the multi-stage random sampling. Data were collected using some instruments including borderline personality feature scale for children, young schema questionnaire-short form, difficulties in emotion-regulation scale(DERS), dissociative experience scale and beck suicide ideation scale. Data were analyzed using the Pearson correlation coefficient and multivariate regression analysis. Results: The results showed a significant positive correlation between schema, emotion regulation, dissociative experiences and suicide ideation with borderline personality features. Moreover, the results of multivariate regression analysis suggested that among the studied variables, schema was the most effective predicting variable of borderline features $(\mathrm{P}<0.001)$.

Conclusions: The findings of this study are in accordance with findings from previous studies, and generally show a meaningful association between schema, emotion regulation, dissociative experiences, and suicide ideation with borderline personality features.
\end{abstract}

Keywords: Borderline Personality Disorder; Schema; Dissociative Disorders; Suicide

\section{Background}

Personality disorders (PD) are associated with ways of thinking and feeling about oneself and others that significantly and adversely affect how an individual functions in many aspects of life. Since the fifth edition of the diagnostic and statistical manual of mental disorders (DSM-5) has shifted to a single axis system, the arbitrary boundaries between PD and other mental disorders have removed (1). Considering that DSM refers to adolescence as the outset of PD, suggesting that symptoms can be traced back in early ages. Supporting this point, some researchers have shown that specific features of borderline personality disorder (BPD), including self-harm, impulsivity and affective instability being detected in childhood, are predictors of BPD in adulthood. As a matter of fact, DSM's wording continues to allow for the diagnosis of PD in child and adolescent populations (2).

Considering the age variable, PD categories may be used for those children and adolescents that their personality features appear to be pervasive, persistent and are not confined to a specific developmental stage or an episode of an axis I disorder. To diagnose PD in individuals under 18 years old, the features must have been presented for at least one year (1). The main defining element is that the BPD symptomatology over 1-year or longer must be severe and persistent enough to disturb adolescent's daily functions. Many of clinical researchers and personality theorists proposed that manifestation of personality disorders can be identified during adolescence and even earlier and this has been mentioned in diagnostic criteria of DSM (2).

Investigating the borderline personality (BP) etiology, cognitive theories are based on schemata, which is a set of generalizations about oneself, others and the world (3). When these schemata are formed, induce advances in processing subsequent information, and consequently enforce more cognitive distortions, such as alternating between extremes of idealization and devaluation and identity disturbance, which are features of BPD (4).

Some theorists suggest that emotional dysregulation is the core feature of BPD (5). The bio-social model (Lin-

Copyright (C) 2015, Zahedan University of Medical Sciences. This is an open-access article distributed under the terms of the Creative Commons Attribution-NonCommercial 4.0 International License (http://creativecommons.org/licenses/by-nc/4.0/) which permits copy and redistribute the material just in noncommercial usages, provided the original work is properly cited. 
han, 1993) is the most influential theory of these theories. More specifically, it is believed that BPD emerges from reciprocal effect of biological vulnerability (extremist emotion temperament) and invalidating environment (grading from average invalidation to extremely high). During development, if an emotive inborn response issued from a child is not replied adequately by the caregiver; therefore, the ability to present self-controlling or inhibit inappropriate emotional responses will never be learnt and this leads to fluctuations among emotional suppression and extreme emotion manifestations. When intense emotional reactions persistently occur during months and years, emotional dysregulations begin to become personality features resulting in social isolation and unstable relationships. Although these features are unadaptive as a result of emotion regulation and avoiding functionality, they are frequent and reinforcing. Consequently early vulnerabilities versus learning history, forms and preserves unadaptive aspects including cognitive, interpersonal, behavioral and emotional characteristics and eventually leads to BPD (6).

Dissociation is disruption in the integrated functions of perception, consciousness, identity and memory. Patients with BPD undergo average to intense dissociative experiences, such as amnestic dissociation and depersonalization (7). Researchers divided dissociation phenomena into the subtypes "psychological" (such as derealization and depersonalization) and "somatoform" (such as analgesia and tonic immobility). Stiglmayr et al. (8) assert that patients with BPD experience somatoform on an average of $17 \%$ and psychological dissociation on an average of $20 \%$ in 24 hours. Generally, $33.3 \%$ of the patients with BPD experience severe somatoform and $41.7 \%$ experience psychological dissociation (8).

Indeed, Barnow et al. (9) acknowledge that dissociation can't be simply regarded as a learned strategy to reduce emotional involvement, but must be regarded as a dysfunctional strategy to regulate emotions, also inducing stress and autonomic output. This is supported by studies have demonstrated that dissociation leads to deficit in emotional regulation and emotion identification (10), and that dissociative processes avoids emotional learning (11). Moreover, Kleindienst et al. (12) showed that dissociation predicts inefficient therapeutic consequences in patients with BPD under a dialectical behavioral therapy. In sum, it seems reasonable that dissociative patients react with dissociation as a response to negative emotions in psychotherapy and suppress their emotional responses that conclude in undesirable outcome.

Severe against stressor factors define patients with BPD and those with suicidal and self-destructive attempt (8). Clinicians are well aware of the fear of abandonment in patients with BPD. This may be the most outstanding feature of the disorder because it informs clinician about the disorganized attachment styles, which patients with BPD deal with. When individuals need solidarity, abandonment is a new internalization of an intolerable strange self-image followed by self-destruction. Suicide reflects imaginary destruction of the strange individual internally. Committing suicide in BPD patients mostly aims to anticipate the probability of abandonment, attempting to preserve the relationship (13). Genetic factors also play an important role in BPD suicidal attempts. Moreover, environment-inheritance interactions explain that environment alter the form of suicide genetic factors (14). Therefore, repeated suicides in patients with BPD have high prevalence, with a lifelong risk of $10 \%$ (15). In adolescents suicide rate is $16.9 \%$ and the suicidal attempt rate is $8.5 \%$ (16). The prevalence of nonsuicidal self-injury is also high, $38-67 \%$ in clinical samples and 10 - 44\% in nonclinical population (17).

\section{Objectives}

The purpose of this study was to determine the relationship between schema, emotion regulation, dissociative experiences, and suicide ideation and BP features in nonclinical population under 18 years old and to explore the quality of the relationship in nonclinical population. Gaining the theoretical objectives leads to more knowledge about BPD and the practical dimensions help to recognize specific patterns in BPD and attribute experimental evidences to clinicians for identification of effective factors in formation of BPD under 18 years old. Accordingly, this study aimed to evaluate if schema, emotion regulation, dissociative experiences and suicide ideation can predict BPD features in students.

\section{Patients and Methods}

In this descriptive correlational study, 300 students (150 boys and 150 girls) were selected from the high schools of Shiraz City, Iran, using the multi-stage random sampling. Data were collected using some instruments including borderline personality feature scale for children (BPFS-C), young schema questionnaire (YSQ)-short form, difficulties in emotion-regulation scale (DERS), dissociative experience scale (DES) and beck suicide ideation scale (SSI). The data obtained by the questionnaires were analyzed by Pearson correlation coefficient and multivariate regression.

\subsection{Participants}

Students from four regions in Shiraz City, studying in $1^{\text {st }}$ to $3^{\text {rd }}$ grades of high school in educational year $2012-2013$ were solicited to participate in the questionnaire surveys. The sample included 300 students (half male and half female) selected using the multistage random sampling. The age range of the participants was 14 to 18 years, with the mean age of 15.72 and standard deviation of 0.99 . Forty-five percent of the participants were in $1^{\text {st }}$ grade, $41 \%$ in $2^{\text {nd }}$ grade and $14 \%$ in $3^{\text {rd }}$ grade of high school. The average cumulative grade point average (CGPA) of students in sample was $17.14, \mathrm{SD}=1.92$. 
Sajadi SF et al.

\subsection{Instruments}

Each participant filled out the following 5 questionnaires:

\subsubsection{Borderline Personality Features Scale for Children}

(BPFS-C: Crick, Murray-Close, and Woods, 2005): This is a 24-item self-report questionnaire that assesses borderline personality features among children and adolescents aged 9-17 (18). This measure was adopted from the BOR (borderline) scale of the personality assessment scale (PAI; Morey, 1991), modified for use with youth. Borderline personality features scale for children is scored on 5-point Likert scale with responses ranging from 1 "not at all true" to 5 "always true" to evaluate affective instability, identity problems, negative relationships and self-harm (19). The BPFS-C has shown good internal consistency across 12 months study by Crick et al. (18), done on a sample of 400 students aged 10-12, $(\alpha>0.76)$ as well as criterion validity (20) and construct validity (18). Prior research in Iran examining the 22-item instruments with a large community sample $(\mathrm{n}=400)$ of boys and girls in high school showed high consistency $(\alpha>0.84)$ (21). In the current study, Cronbach's $\alpha$ was 0.83 .

\subsubsection{The Young Schema Questionnaire, Short-Form}

(YSQ-SF: Young \& Brown, 1990) is a 75-item self-report questionnaire that evaluate 15 early maladaptive schemas belonging to five schema domains as postulated by Young et al. (3). Each item is formulated as a negative belief about the self and rated on 6 -point Likert scale $(1=$ completely untrue of me, 6 = completely describes me). An individual schema score is obtained by averaging scores on the five items each schema consists of. The Iranian translation of the YSQ-short form (22) demonstrates good psychometric properties. In the current study, abandonment/instability and emotional deprivation were the 2 sub-scales, related to borderline personality features that were studied and Cronbach's $\alpha$ for each was 0.72 and 0.75 , respectively.

\subsubsection{Difficulties in Emotion-Regulation Strategies Scale}

(DERS: Gratz \& Roemer, 2004): The DERS consists of 36 items that are rated on a 5-Likert scale, ranging from 1 (almost never, (0 - 10\%), 2 (sometimes, 11 - 35\%), 3 (about half the time, 36 - 65\%), 4 (most of the time, 66 - 90\%) and 5 (almost always, 91-100\%). The higher scores indicate higher difficulties in emotion regulation. This scale provides a comprehensive assessment of difficulties in emotion regulation, including nonacceptance, difficulty in engaging goal-oriented behaviors (goals), impulse controlling difficulties (impulse), lack of emotional awareness (aware), limited access to emotion-regulation strategies (strategies) and lack of emotional clarity (clarity). Prior research examining this instrument in a clinical samples $(n=111)$ demonstrated high internal consistency $(\alpha>0.86)$ (23). In Iranian sample, this scale has shown good internal consistency ( $\alpha>0.86)$ (24). In the current study, 2 sub- scales used were difficulties engaging in goal-directed behavior (goals) and impulse control difficulties (impulse), assumed to be indicating borderline personality feature. Cronbach's $\alpha$ for each was 0.76 and 0.67 , respectively.

\subsubsection{Dissociative Experience Scale}

(DES: Bernstein \& Putnam, 1986): DES is a 28-item self-report measure with a 10-point scale ranging from "never" (0\%), to "always" (100\%). Each item describes a kind of experience that the subjects may have had. Studies showed that a grade higher than 15 needs more investigation to diagnose dissociation, a score higher than 30 indicates high probability of dissociative disorders and PTSD, and scores over 40 express high probability of dissociative identity disorder (25). Factor analysis has revealed three factor structures and these subscales can be scored separately (26), including amnestic dissociation (e.g. finding new objects in your stuff that you don't remember buying), depersonalization and derealization (e.g. feeling that your body doesn't belong to you) and imaginative involvement (e.g. being in a familiar place but assigning as strange) (27). Construct validity studies have been reported by Frischholz et al. (28). These findings indicate good concurrent and criterion related validity. Olsen and Beck (29) reported high internal consistency of DES with a Cronbach's $\alpha$ of 0.7. Cronbach's $\alpha$ in Iranian sample was $0.96(25)$. In current study Cronbach's $\alpha$ was 0.92 .

\subsubsection{Scale for Suicide Ideation}

(SSI; Beck et al.1979): SSI is a 19-item self-report questionnaire designed to measure severity of attitude, behaviors and plans to complete suicide. It assesses death wish, active/inactive tendency to suicide, length and plentitude of suicidal thoughts, self-control, inhibitors and readiness to commit suicide (30). The items are scored on a 3 -point scale from 0 to 2 . The total score may vary from 0 to 38 , with higher scores indicating more intense levels of suicidal ideation (31). The SSI has demonstrated good psychometric properties for psychiatric outpatients (32). Another study reported high internal consistency of SSI with Cronbach's of 0.89 (33). Cronbach's $\alpha$ in Iranian samples varies from 0.87 to 0.97 (30). In the current sample, Cronbach's $\alpha$ was 0.9.

\section{Results}

Descriptive statistics and findings of this study were presented in this section. Table 1 included descriptive information, Mean and standard deviation(SD) of the variables. According to the data presented in Table 1, the Mean (SD) score obtained by the sample $(\mathrm{n}=300)$ on variable of borderline personality features was 58.983 (1.244), schema 33.023 (9.861), emotion regulation 23.833 (8.910), dissociative experiences 30.233 (1.649) and suicidal ideation 5.296 (6.412).

To investigate the relationship between borderline personality features and schema, emotion regulation, dis- 
Sajadi SF et al.

sociative experiences, and suicidal ideation in the total scale and subscales, a matrix for Pearson correlation coefficient was calculated. The summary of findings is given in (Table 2). Considering the Table 2, all variables in the study have a positive correlation with each other, alpha coefficients range from 0.2 to 0.88 , and all the correlations are significant at $\mathrm{P}<0.001$.

As seen in Table 2, correlation coefficients between borderline personality features and schema, emotion regulation, dissociative experiences and suicidal ideation were $0.57,0.53,0.46,0.45$, respectively $(\mathrm{P}<0.001)$. To assess a more accurate predictive role for schema, emotion regulation, dissociative experiences and suicidal ideation, a multivariate regression analysis (stepwise) was used. The results of the analysis were shown in Table 3.

Table 1. Mean and Standard Deviation of Student's Scores on Research Variables

\begin{tabular}{lccc}
\hline Variable & Mean \pm SD & Minimum & Maximum \\
\hline Borderline personality features & $58.98 \pm 1.24$ & 31.00 & 98.00 \\
\hline Affective instability & $15.26 \pm 3.61$ & 6.00 & 24.00 \\
\hline Identity problems & $14.81 \pm 4.19$ & 6.00 & 25.00 \\
\hline Negative relationships & $14.28 \pm 3.92$ & 6.00 & 26.00 \\
Self-harm & $14.62 \pm 4.12$ & 6.00 & 28.00 \\
\hline Schema & $33.02 \pm 9.86$ & 10.00 & 58.00 \\
Emotional deprivation & $15.03 \pm 6.03$ & 5.00 & 30.00 \\
Abandonment/instability & $17.99 \pm 6.00$ & 5.00 & 30.00 \\
Emotion regulation & $23.83 \pm 8.91$ & 4.00 & 44.00 \\
\hline Goals & $12.68 \pm 4.62$ & 1.00 & 20.00 \\
Impulse & $11.15 \pm 6.04$ & 00.00 & 24.00 \\
Dissociative experiences & $30.23 \pm 1.65$ & 0.36 & 77.50 \\
\hline Suicidal ideation & $5.29 \pm 6.41$ & 0 & 34.00 \\
\hline
\end{tabular}

Table 2. Correlation Matrix for Research Variables ${ }^{a}$

\begin{tabular}{|c|c|c|c|c|c|c|c|c|c|c|c|c|}
\hline Variables & $\mathbf{1}$ & 2 & 3 & 4 & 5 & 6 & 7 & 8 & 9 & 10 & $\mathbf{1 1}$ & 12 \\
\hline Borderline Personality features & - & - & - & - & - & - & - & - & - & - & - & - \\
\hline Affective instability & 0.75 & - & - & - & - & - & - & - & - & - & - & - \\
\hline Identity problems & 0.78 & 0.47 & - & - & - & - & - & - & - & - & - & - \\
\hline Negative relationships & 0.79 & 0.50 & 0.47 & - & - & - & - & - & - & - & - & - \\
\hline Self-harm & 0.79 & 0.44 & 0.49 & 0.53 & - & - & - & - & - & - & - & - \\
\hline Schema & 0.57 & 0.38 & 0.53 & 0.43 & 0.42 & - & - & - & - & - & - & - \\
\hline Emotional deprivation & 0.48 & 0.30 & 0.36 & 0.43 & 0.41 & 0.82 & - & - & - & - & - & - \\
\hline Abandonment/instability & 0.45 & 0.32 & 0.50 & 0.28 & 0.28 & 0.81 & 0.34 & - & - & - & - & - \\
\hline Emotion regulation & 0.53 & 0.57 & 0.37 & 0.38 & 0.37 & 0.36 & 0.31 & 0.29 & - & - & - & - \\
\hline Goals & 0.40 & 0.40 & 0.29 & 0.34 & 0.22 & 0.26 & 0.20 & 0.22 & 0.78 & - & - & - \\
\hline Impulse & 0.48 & 0.53 & 0.32 & 0.29 & 0.38 & 0.34 & 0.30 & 0.25 & 0.88 & 0.39 & - & - \\
\hline Dissociative experiences & 0.46 & 0.36 & 0.41 & 0.30 & 0.38 & 0.34 & 0.28 & 0.27 & 0.42 & 0.27 & 0.41 & - \\
\hline Suicidal ideation & 0.45 & 0.28 & 0.27 & 0.43 & 0.42 & 0.37 & 0.43 & 0.17 & 0.30 & 0.17 & 0.31 & 0.27 \\
\hline
\end{tabular}

a Values are correlation coefficients.

Table 3. The Results of Stepwise Regression in Predicting Borderline Personality Features a

\begin{tabular}{|c|c|c|c|c|c|c|c|c|}
\hline Variables & $\mathbf{R}$ & $\mathbf{R}^{2}$ & $\mathbf{F}$ & FChange & R Square Change & $\beta$ & t & $\mathbf{P}$ \\
\hline schema & 0.57 & 0.32 & 143.4 & 143.4 & 0.32 & 0.57 & 11.97 & $<0.001$ \\
\hline Schema & 0.66 & 0.44 & 120.3 & 65.98 & 0.12 & 0.43 & 9.28 & $<0.001$ \\
\hline Emotion regulation & & & & & & 0.37 & 8.12 & $<0.001$ \\
\hline Schema & 0.69 & 0.48 & 92.93 & 21.51 & 0.03 & 0.36 & 7.81 & $<0.001$ \\
\hline Emotion regulation & & & & & & 0.33 & 7.35 & $<0.001$ \\
\hline Suicidal ideation & & & & & & 0.21 & 4.63 & $<0.001$ \\
\hline Schema & 0.71 & 0.51 & 77.15 & 15.83 & 0.02 & 0.33 & 7.15 & $<0.001$ \\
\hline Emotion regulation & & & & & & 0.27 & 5.86 & $<0.001$ \\
\hline Suicidal ideation & & & & & & 0.19 & 4.27 & $<0.001$ \\
\hline Dissociative experiences & & & & & & 0.18 & 3.98 & $<0.001$ \\
\hline
\end{tabular}


Regression analysis illustrated that all variables were used in analysis and suicidal ideation, schema, emotion regulation and dissociative experiences respectively had most important role in predicting borderline personality features. $\mathrm{R}, \mathrm{R}^{2}$ reported to be 0.45 and 0.2 , respectively, meaning that $20 \%$ of the borderline personality features' variance in study subjects are explained by suicidal ideation, schema, emotion regulation and dissociative experiences. F for multiple correlations calculated to be 76.00 $(\mathrm{P}<0.001)$

\section{Discussion}

The findings of the present study show that suicidal ideation, schema, emotion regulation and dissociative experiences are respectively predictors of personality disorder features. Our study findings are similar to those of Lyons-Ruth et al. (16), Legris et al. (34), Zanarini et al. (35), Hulbert and Thomas (36), considering the relationship between suicidal ideation and borderline personality features. These findings support the assumption that suicidal ideation and attempts are correlated with many kinds of risk factors but maybe the most related to the basic construct of suicidal behavior are personality factors. One of the three personality features acting as an infrastructure of suicide is impulsivity and aggressive characteristics combined with an over sensitivity to minor life events. This sensitivity often leads to anxious reactions companied with secondary depression. These subjects tend to use defense mechanisms such as regression, splitting, dissociation and displacement and probably suffering from physical and sexual abuse in their childhood. These patients may be characterized as suffering from "borderline" personality disorder (37).

The results of the study in the case of schema and borderline personality features are consistent with the results of Jovev and Jackson (38), Sempertegui et al. (39), Reeves and Taylor (40). The findings resemble a pattern of defected childhood schema in personality disorders specifically borderline personality. To explain fluctuating moods and impulsive behaviors in borderline personality patients, Young et al. (3) presented a model based on which borderline patients provoked by environmental stimuli, often return back to intense emotional experiences in childhood. In these situations, schema state which is an organized pattern of thought, emotion and behavior, activates independently (41).

Considering the connection between emotion regulation and borderline personality features, our results are consistent with those of Rosenthal et al. (42), Trull et al. (43), Gratz et al. (44). Emotion dysregulation thought to be relevant to BPD includes several lower-order emotive features, such as anxiousness and affective liability (the tendency to experience fluctuations in affective states), emotional intensity (the tendency to experience intense emotions), emotional reactivity (severe reactions to slight emotional events) sensitivity (the tendency to react quickly to stimuli) and affective instability (reactive shifts in mood), which all are related to borderline personality pathogenesis (45).

Our findings regarding the relationship between borderline personality features and dissociation are similar to the results of Evren et al. (46), Zanarini et al.(7), Ebner-Priemer et al. (47). It can be explained that dissociative experiences are correlated with negative emotions (46). Clinical experiences support the theory that dissociative experiences in borderline patients starts with his belief about harmful mental pressures and dissociation mostly happens while experiencing stress. Dissociation occurs in 2/3 of borderline patients and dissociative experiences have a positive relationship with borderline personality features intensity $(48,49)$. Furthermore, experimental studies found reduced pain sensitivity in patients with BPD under stress conditions and revealed a significant correlation between self-reported pain insensitivity and dissociative features (50). These results suggest that personal difference in dissociation among borderline patients can explain the apparent discrepancies in findings of psychological studies. Several limitations to this study are noteworthy. First, since this research is a correlational study, thus it does not represent the casual relationships between variables. Consequently, compared to experimental and semi-experimental studies, these kinds of researches have less authentication. Another limitation is restricting sample to high school students due to methodology. It is suggested to perform similar researches on larger samples of borderline patients in other age groups to determine quality of the relationship and be able to present more reliable and generalized information. In addition, other sex, social and economic groups may be also taken into account to expand findings. Therefore, it is suggested that more studies investigating these factors can obviously lead to clearer results.

\section{Acknowledgements}

We thank all study participants for their motivation and participation in our study and Shiraz Department of Education for their support. This work was in part supported by the Shahid Chamran University of Ahvaz (Department of Psychology).

\section{Authors' Contributions}

Seyede Fateme Sajadi was responsible for analysis and interpretation of data, drafting of the manuscript, statistical analysis. Zahra Hajjari was responsible for acquisition of data. Nasrin Arshadi was responsible for administrative, technical, and material support. Yadolla Zargar was responsible for study concept and design. Mahnaz Mehrabizade Honarmand was responsible for critical revision of the manuscript for important intellectual content.

\section{References}

1. Association AP. Diagnostic and Statistical Manual of Mental Disorders :DSM 5.5 ed: American Psychiatric Association; 2013. 
2. Miller AL, Muehlenkamp JJ, Jacobson CM. Fact or fiction: diagnosing borderline personality disorder in adolescents. Clin Psychol Rev. 2008;28(6):969-81.

3. Young JE, Klosko JS, Weishaar ME. Schema therapy: A practitioner's guide. New York: Guilford Press; 2003.

4. Beck AT, Davis DD, Freeman A. Cognitive Therapy of Personality Disorders. Guilford Publications; 1990.

5. Crowell SE, Beauchaine TP, Linehan MM. A biosocial developmental model of borderline personality: Elaborating and extending Linehan's theory. Psychol Bull. 2009;135(3):495-510.

6. Winsper C. The developmental precursors of borderline personality disorder symptoms at 11 years in a British cohort. University of Warwick; 2012

7. Zanarini MC, Ruser TF, Frankenburg FR, Hennen J, Gunderson JG. Risk factors associated with the dissociative experiences of borderline patients. J Nerv Ment Dis. 2000;188(1):26-30.

8. Stiglmayr CE, Shapiro DA, Stieglitz RD, Limberger MF, Bohus M. Experience of aversive tension and dissociation in female patients with borderline personality disorder - a controlled study. J Psychiatr Res. 2001;35(2):111-8.

9. Barnow S, Limberg A, Stopsack M, Spitzer C, Grabe HJ, Freyberger $\mathrm{HJ}$, et al. Dissociation and emotion regulation in borderline personality disorder. Psychol Med. 2012;42(4):783-94.

10. Kaplow JB, Hall E, Koenen KC, Dodge KA, Amaya-Jackson L. Dissociation predicts later attention problems in sexually abused children. Child Abuse Negl. 2008;32(2):261-75.

11. Steidl S, Mohi-uddin S, Anderson AK. Effects of emotional arousal on multiple memory systems: evidence from declarative and procedural learning. Learn Mem. 2006;13(5):650-8.

12. Kleindienst N, Limberger MF, Ebner-Priemer UW, Keibel-Mauchnik J, Dyer A, Berger M, et al. Dissociation predicts poor response to Dialectial Behavioral Therapy in female patients with Borderline Personality Disorder. J Pers Disord. 2011;25(4):432-47.

13. Fonagy P, Leigh T, Steele M, Steele H, Kennedy R, Mattoon G, et al The relation of attachment status, psychiatric classification, and response to psychotherapy. J Consult Clin Psychol.1996;64(1):22-31.

14. Caspi A, Sugden K, Moffitt TE, Taylor A, Craig IW, Harrington H, et al. Influence of life stress on depression: moderation by a polymorphism in the 5-HTT gene. Science. 2003;301(5631):386-9.

15. Stanley B, Brodsky B. Risk factors and treatment of suicidality in borderline personality disorder. Clin Neurosci Res. 2001;1(5):351-61.

16. Lyons-Ruth K, Bureau JF, Holmes B, Easterbrooks A, Brooks NH. Borderline symptoms and suicidality/self-injury in late adolescence: prospectively observed relationship correlates in infancy and childhood. Psychiatry Res. 2013;206(2-3):273-81.

17. Nixon MK, Heath NL. review of population and clinical studies in adolescence. In: Heath NL, Schaub K, Holly S, Nixon MK, editors. Self-Injury in Youth: The Essential Guide to Assessment and Intervention. Taylor \& Francis; 2009.

18. Crick NR, Murray-Close D, Woods K. Borderline personality features in childhood: a short-term longitudinal study. Dev Psychopathol. 2005;17(4):1051-70.

19. Sharp C, Ha C, Michonski J, Venta A, Carbone C. Borderline personality disorder in adolescents: evidence in support of the Childhood Interview for DSM-IV Borderline Personality Disorder in a sample of adolescent inpatients. Compr Psychiatry. 2012;53(6):765-74.

20. Chang B, Sharp C, Ha C. The criterion validity of the Borderline Personality Features Scale for Children in an adolescent inpatient setting. J Pers Disord. 2011;25(4):492-503.

21. Sajadi SF. Designing and testing a model of some precedents and outcomes of borderline personality disorder in high school students of Shiraz. Ahvaz, Iran: Shahid Chamran University of Ahvaz;2013.

22. Ahi G, Mohamadifar MA, Besharat MA. [Validity and reliability of Young Schema Questionnaire, short-form]. J Psychol Educ. 2007;3(37):5-20.

23. Sharp C, Pane H, Ha C, Venta A, Patel AB, Sturek J, et al. Theory of mind and emotion regulation difficulties in adolescents with borderline traits. J Am Acad Child Adolesc Psychiatry. 2011:50(6):563-573 e1

24. Alavi KH, Modares M, Yazdi SA. [The effectiveness of dialectical behavior group therapy on depression symptoms in university
students].J Fundamentals Ment Health . 2011;13(2)

25. Kianpoor M, Ghanizadeh A, Badiei H. The Relationship between Dissociative Experiences and the Success of Treatment through Abstinence from Opioid-Use Disorders. Zahedan J Res Med Sci. 2012;14(10):56-60.

26. BURCHJP.Alexithymia and dissociation. USA:University of Oregon; 1995.

27. Renard SB, Pijnenborg M, Lysaker PH. Dissociation and social cognition in schizophrenia spectrum disorder. Schizophr Res. 2012;137(1-3):219-23.

28. Frischholz EJ, Braun BG, Sachs RG, Schwartz DR, Lewis J, Shaeffer D, et al. Construct validity of the Dissociative Experiences Scale: II. Its relationship to hypnotizability. Am J Clin Hypn. 1992;35(2):145-52.

29. Olsen SA, Beck JG. The effects of dissociation on information processing for analogue trauma and neutral stimuli: a laboratory study. J Anxiety Disord. 2012;26(1):225-32.

30. Anisi J, Fathi Ashtiani A, Salimi SH, Ahmadi K. Validity and Reliability of Beck Suicide Scale Ideation among soldiers. J Mil Med. 2005;7(1):33-7.

31. Witte TK, Joiner TJ, Brown GK, Beck AT, Beckman A, Duberstein $\mathrm{P}$, et al. Factors of suicide ideation and their relation to clinical and other indicators in older adults. J Affect Disord. 2006;94(13):165-72.

32. Beck AT, Brown GK, Steer RA. Psychometric characteristics of the Scale for Suicide Ideation with psychiatric outpatients. Behav Res Ther.1997;35(11):1039-46.

33. Wasserman D. Suicide: An Unnecessary Death. Taylor \& Francis; 2001.

34. Legris J, Links PS, van Reekum R, Tannock R, Toplak M. Executive function and suicidal risk in women with Borderline Personality Disorder. Psychiatry Res. 2012;196(1):101-8.

35. Zanarini MC, Laudate CS, Frankenburg FR, Reich DB, Fitzmaurice G. Predictors of self-mutilation in patients with borderline personality disorder: A 10-year follow-up study. J Psychiatr Res. 2011;45(6):823-8.

36. Hulbert C, Thomas R. Predicting self-injury in BPD: an investigation of the experiential avoidance model. J Pers Disord. 2010;24(5):651-63.

37. Apter A. Clinical aspects of suicidal behavior relevant to genetics. Eur Psychiatry. 2010;25(5):257-9.

38. Jovev M, Jackson HJ. Early maladaptive schemas in personality disordered individuals. J Pers Disord. 2004;18(5):467-78.

39. Sempertegui GA, Karreman A, Arntz A, Bekker MH. Schema therapy for borderline personality disorder: a comprehensive review of its empirical foundations, effectiveness and implementation possibilities. Clin Psychol Rev. 2013;33(3):426-47.

40. Reeves M, Taylor J. Specific relationships between core beliefs and personality disorder symptoms in a non-clinical sample. Clin Psychol Psychother. 2007;14(2):96-104.

41. Arntz A, Klokman J, Sieswerda S. An experimental test of the schema mode model of borderline personality disorder. J Behav Ther Exp Psychiatry. 2005;36(3):226-39.

42. Rosenthal MZ, Cheavens JS, Lejuez CW, Lynch TR. Thought suppression mediates the relationship between negative affect and borderline personality disorder symptoms. Behav Res Ther 2005;43(9):1173-85

43. Trull TJ, Widiger TA, Lynam DR, Costa PJ. Borderline personality disorder from the perspective of general personality functioning. J Abnorm Psychol. 2003;112(2):193-202.

44. Gratz KL, Latzman RD, Tull MT, Reynolds EK, Lejuez CW. Exploring the association between emotional abuse and childhood borderline personality features: the moderating role of personality traits. Behav Ther. 2011;42(3):493-508.

45. Skodol AE, Gunderson JG, Pfohl B, Widiger TA, Livesley WJ, Siever LJ. The borderline diagnosis I: psychopathology, comorbidity, and personality structure. Biol Psychiatry. 2002;51(12):936-50.

46. Evren C, Cinar O, Evren B. Relationship of alexithymia and dissociation with severity of borderline personality features in male substance-dependent inpatients. Compr Psychiatry. 2012;53(6):854-9.

47. Ebner-Priemer UW, Badeck S, Beckmann C, Wagner A, Feige B, 


\section{Sajadi SF et al.}

Weiss I, et al. Affective dysregulation and dissociative experience in female patients with borderline personality disorder: a startle response study.J Psychiatr Res. 2005;39(1):85-92.

48. Korzekwa MI, Dell PF, Links PS, Thabane L, Fougere P. Dissociation in borderline personality disorder: a detailed look. JTrauma Dissociation. 2009;10(3):346-67.
49. Karadag F, Sar V, Tamar-Gurol D, Evren C, Karagoz M, Erkiran M Dissociative disorders among inpatients with drug or alcohol dependency. JClin Psychiatry. 2005;66(10):1247-53.

50. Schmahl C, Bohus M, Esposito F, Treede RD, Di Salle F, Greffrath W, et al. Neural correlates of antinociception in borderline personality disorder. Arch Gen Psychiatry. 2006;63(6):659-67. 